\section{BCWA: don't we love abbreviations and acronyms!}

\author{
Philip Wiffen
}

Intriguing? Confusing? Annoying? Abbreviations are a shortening of a word often to a letter or two so pharmacists will be familiar with Latin abbreviations such as tds. An acronym is a word formed from the initial letters of other words. In practice, it seems the two terms are somewhat interchangeable.

This editorial is one of my occasional trips into encouraging authors to compose good papers. The editorial on abstracts is still widely used. ${ }^{1}$ I have noticed an increasing number of abbreviations/acronyms creeping into submissions, often created by the authors themselves and not in use anywhere else. I appreciate that they are useful in reducing the word count but we do not penalise authors who slightly exceed the count, however they can be annoying when some way through a paper an abbreviation appears that was defined on the first page and you have to go back and find it! Some abbreviations are so widely used that they really need no explanation. COVID-19 is now firmly in our vocabularies but many would not know what the individual letters stand for-it is actually a reduction of Coronovirus disease.

Correspondence to Professor Philip Wiffen, Pain Research Unit, Churchill Hospital, Oxford OX3 7LE, UK; pwiffen@oxfordsrs.org.uk
BCWA?-I didn't make this up, I heard while assisting at a systematic review course at Nottingham University. Of course it's always possible to pop an abbreviation into a search engine but this is often not helpful. Here are a few that I came across in submissions in the last two or three weeks:

MBDS—this could be management of big data systems or the Mekong Basin Disease Surveillance or possibly a business in the USA. The authors intended it as 'minimum basic data set'.

NA - not applicable? It could be notapplicable, or Narcotics Anonymous but in this case was 'naranjo algorithm' SA-a more tricky one. South Africa? No! The authors intended sensitivity analysis.

There are many more such examples. Hopefully you get the point.

Interestingly, there is literature on this subject. A paper by $\mathrm{Mack}^{2}$ suggests the following:

- An acronym should speed up the reading and ease the understanding of the content of a paper. The goal of acronym use generally requires that the abbreviation be familiar, so don't make up acronyms.

- It should save space and/or prevent cumbersome repetition.
It should only be used if it appears regularly throughout the text (say, five or more times) or because it is commonly known and understood.

Furthermore, don't use acronyms in the title or the abstract (the latter is particularly annoying as it is often not explained). The acronym should be spelt out the first time it is used and also spell it out if used in a figure.

If you stick to this, you won't go far wrong.

So what is the meaning of BCWA? Be careful with abbreviations!

Funding The authors have not declared a specific grant for this research from any funding agency in the public, commercial or not-for-profit sectors.

Competing interests None declared.

Provenance and peer review Commissioned; internally peer reviewed.

(c) European Association of Hospital Pharmacists 2021. No commercial re-use. See rights and permissions. Published by BMJ.

$$
\text { A Check for updates }
$$

To cite Wiffen P. Eur J Hosp Pharm 2021;28:241.

Published Online First 28 July 2021

Eur J Hosp Pharm 2021;28:241.

doi:10.1136/ejhpharm-2021-002981

ORCID iD

Philip Wiffen http://orcid.org/0000-0001-6085-1307

\section{REFERENCES}

1 Wiffen P. If only abstracts were more concrete! Eur J Hosp Pharm 2016;23:125.

2 Mack C. How to write a good scientific paperacronyms. Available: http://www. lithoguru.com/ scientist/litho_papers/JM3\%20editorial\%202012\% 20q4_Acronyms.pdf 